\title{
Memória, identidade e campesinato: tecendo a Geografia do hoje e do ontem no campo
}

\author{
Memoria, identidad y campesinado: tejiendo la geografía de \\ hoy y de ayer en el campo
}

\author{
Memory, Identity and Peasantry: weaving Today's and \\ Yesterday's Geographies on Land
}

\author{
Larissa Urquiza Perez de Morais \\ lahurquiza@gmail.com \\ Universidade Federal do Paraná, UFPR, PR \\ Gustavo Felipe Olesko \\ gustavo.olesko@gmail.com \\ Universidade de São Paulo, USP, SP
}

Resumo: Esse trabalho tem por objetivo explicitar a importância dos estudos sobre memória e identidade para a Geografia Agrária, focando na construção do campesinato como classe social com identidade própria, construída ao longo de lutas. Utilizando trabalhos de historiadores e antropólogos, procuramos conceituar memória e identidade para então discutirmos o campesinato e suas relações, especialmente no tocante da luta pela terra e território

Palavras-chave: Classe camponesa, Território, Resistência, Identidade, Memória

Resumen: Este artículo tiene como objetivo explicar la importancia de los estudios sobre la memoria y la identidad para la Geografía Agraría, centrándose en la construcción del campesinado como clase social con identidad propia, construida a lo largo de las luchas. Utilizando obras de historiadores y antropólogos, tratamos de conceptualizar la memoria y la identidad para luego discutir el campesinado y sus relaciones, especialmente en lo que se refiere a la lucha por la tierra y el territorio.

Palabras clave: Clase Campesina, Territorio, Resistencia, Identidad, Memoria.

Abstract: This paper aims to explain the value of the memory and identity studies to Geography, focusing on the making peasantry as class with an own identity, built along fights. Employing historians and anthropologists' works, we search to conceptualize memory and identity to discuss peasantry and their relations, especially in the struggle for land and territory.

Keywords: Peasantry Class, Territory, Resistance, Identity, Memory. 


\section{INTRODUÇÃO}

Os estudos sobre memória e identidade nas Ciências Humanas mostram que as memórias são construídas e estão em permanente mudança. Memória e identidade estão intimamente ligadas e por sua vez, no âmbito da Geografia, compreendemos que tais elementos são vitais e indissociáveis da construção territorial e consequentemente, da produção do espaço. Com a intenção de problematizar as relações entre memória, identidade e campesinato na Geografia é que esse trabalho se desenvolverá, focando na construção de identidades no campo. Utilizando conceitos de Michael Pollak e Joel Candau trabalharemos os aspectos teóricos, no que se refere à memória e a construção de identidades através da mesma, dialogando com a História e a Antropologia, elevando memória e identidade a categorias interdisciplinares.

Sendo assim, entende-se que a própria construção da identidade e da memória se dá de modo dialético. No caso do campesinato, compreendemos que suas identidades são múltiplas, assim como suas memórias. A construção de seus territórios de vida e sua produção espacial se dão de modo específico e estão intimamente conectadas as suas identidades e memórias em particular. Todavia, o campesinato é polifônico, diverso, complexo e variado, porém sua definição como classe sui generis do modo de produção capitalista é inegável. O capitalismo é hegemônico no mundo atual, mas hegemonia não é sinônimo de uniformidade. Logo, de acordo com Armando Bartra (2011), Edward P. Thompson (2012), Samir Amin (1977) e Ariovaldo Oliveira (2002), o campesinato é uma classe que, apesar de suas várias peculiaridades e múltiplas construções, se constrói enquanto classe por e a partir das lutas de classes. A conexão entre tais elementos é muito importante para a construção territorial do campesinato e a comunidade e a família são pontos chave do entendimento desta classe. Devemos ter em mente então que a relação escalar é precisa e indispensável, pois apesar de no campesinato existirem as mais diversas identidades, como a faxinalense, a de pescadores artesanais, fundos e fechos de pasto, entre outros, existe uma coesão de classe: todos são camponeses e em seu horizonte está a luta permanente contra a subordinação de sua renda da terra, a luta pela autonomia e pela manutenção digna de suas famílias e comunidade.

Este artigo divide-se em três partes: apresentação das categorias memória e identidade nos trabalhos das Ciências Humanas e a importância desses estudos para a Geografia; discussão acerca da questão da identidade no campesinato enquanto classe e a importância dela para a luta de classes e para a própria questão do campesinato em si; apresentação conclusiva acerca das questões levantadas anteriormente - relação entre memória, identidade e campesinato.

\section{MEMÓRIA E IDENTIDADE: APORTES TEÓRICOS}

A memória é uma das maneiras dos seres humanos sentirem-se pertencentes a algo, a alguém e/ou a um determinado grupo. Vive-se em sociedade e acaba-se por construir 
um sentimento de pertencimento para com o lugar de onde enxerga-se o mundo, criando identidades. Este processo é muito mais complexo do que o senso comum presume essas questões foram exploradas por pesquisadores de diversas áreas da Psicologia, Antropologia, Sociologia, História e Filosofia. A Geografia Agrária nacional ainda carece de estudos teóricos sobre a construção da memória e das identidades e esse artigo pretende esboçar a importância dessas pesquisas.

K.V. Silva e M.H. Silva compilaram conceitos caros à pesquisa histórica como a definição de memória. Em seu Dicionário de Conceitos Históricos (2009, p. 419), vemos que:

Segundo Jacques Le Goff, a memória é a propriedade de conservar certas informações, propriedade que se refere a um conjunto de funções psíquicas que permite ao indivíduo atualizar impressões ou informações passadas, ou reinterpretadas como passadas. [...] A memória está nos próprios alicerces da História, confundindo-se com o documento, com o monumento e com a oralidade. Mas só muito recentemente se tornou objeto de reflexão da historiografia. Só no fim da década de 1970 que os historiadores da Nova História começaram a trabalhar com a memória.

No campo da História, portanto, há necessidade de separação entre história e memória. Neste artigo a memória é encarada como algo lacunoso e fluído, em permanente processo de construção, rememoração, esquecimento e reconfiguração de lembranças. Partindo dessa definição, utiliza-se Michael Pollak $(1989$; 1992) para discutir memória individual e coletiva e a construção das identidades a partir destas.

Pollak (1992), também historiador, afirma que os estudos sobre memória se tornaram mais intensos no campo da História, no período do Pós-Segunda Guerra Mundial, uma vez que o povo europeu, em especial, estava vivendo de modo intenso os traumas da guerra. O ato de lembrar, de não "deixar cair no esquecimento", leva os pesquisadores a se aprofundarem no tema, afim de apresentar os horrores da guerra e estabelecer um lugar de destaque para essas memórias. Ainda para Pollack (1992, p. 2):

A priori, a memória parece ser um fenômeno individual, algo relativamente íntimo, próprio da pessoa. Mas Maurice Halbwachs, nos anos 20-30, já havia sublinhado que a memória deve ser entendida também, ou sobretudo, como um fenômeno coletivo e social, ou seja, como um fenômeno construído coletivamente e submetido a flutuações, transformações, mudanças constantes.

A memória coletiva de um povo, uma nação, ou um grupo pode ser gestionada pelo Estado, quando as memórias hegemônicas de um grupo se sobrepõem ao longo do tempo sobre o restante; pode vir a ser uma memória "resgatada", rememorada a fim de angariar para um determinado grupo uma identidade socialmente construída. Utiliza-se o estatuto da memória para legitimar práticas culturais - religiosas, costumes, crenças, linguagem - até territorialidades e desterritorialidades. Reforça-se que esta categoria de memória é um fenômeno construído consciente e inconscientemente, disposta em função de interesses políticos, pessoais e sociais do tempo presente sendo, portanto o resultado de uma produção, reprodução, edição, ... que ressalta e exclui o que convém aos dominantes. 
Sendo construída individual e socialmente, a memória tem ligação com a identidade, na medida em que também produz esse sentimento que depende, por sua vez, da relação com o 'outro' e 'do outro'. Memória e identidade possuem relação dialética, não harmônica, de contradição e confrontação, numa construção social histórica e territorial que se modifica ao longo do tempo e do espaço.

A humanidade constrói sua identidade a partir de dois elementos constitutivos da memória: os acontecimentos realmente vividos pelo indivíduo e aqueles não vividos por ele, mas vivenciados pelo grupo, comunidade, nação, na qual se está inserido (POLLAK, 1992). Os personagens, lugares e acontecimentos pertencentes a determinada memória direta ou indiretamente - podem remeter a pessoas, lugares e fatos concretos que realmente existiram. No entanto essas referências podem se tratar de projeções e representações de outros eventos por vezes não vividos, por vezes apreendido no grupo (POLLAK, 1992). Como apresentou Marx (1989), de certo modo é a projeção de um ideal no real.

Para Stuart Hall, em Quién Necesita Identidad?, a identidade se dá a partir da 'identificação', que

En el lenguaje del sentido común, la identificación se construye sobre la base del reconocimiento de algún origen común o unas características compartidas con outra persona o grupo o con un ideal, y con el vallado natural de la solidaridad y la lealtad establecidas sobre este fundamento [...] el enfoque discursivo ve la identificación como una construcción, un proceso nunca terminado: siempre 'en proceso'. No está determinado, en el sentido de que siempre es posible 'ganarlo' o 'perderlo', sostenerlo o abandonarlo. Aunque no carece de condiciones determinadas de existencia, que incluyen los recursos materiales y simbólicos necesarios para sostenerla, la identificación es en definitiva condicional y se afinca en la contingencia. Una vez consolidada, no cancela la diferencia. (HALL, 2003, p. 15).

Portanto, o processo de identificação insere a relação do 'eu' com o 'outro', que por sua vez insere a questão da diferença. Numa história passada de geração em geração, por exemplo, surge a identificação de um passado comum ao indivíduo e aos outros - o grupo. Acrescenta-se a isto a relação dialética com a memória como parte fundamental do processo tanto discursivo quanto concreto da construção da memória e da identidade social. A construção deste conceito por Hall (2003) advém do materialismo histórico dialético, nos levando ao real, ao material, em contraste com autores que por vezes preocupam-se mais com aspectos metafísicos.

A identidade, para Pollak (1992), se constrói a partir de três elementos: a unidade física, a continuidade dentro do tempo e o sentimento de coerência. Respectivamente, esses elementos fundamentais significam: as fronteiras materiais onde o indivíduo está inserido; a perspectiva de continuidade no tempo de um grupo ou povo, em sentido moral, psicológico e físico; e por fim, o sentimento de coerência que fornece a base unificada para a formação do indivíduo. Deste modo,

[...] a memória é um elemento constituinte do sentimento de identidade, tanto individual como coletiva, na medida em que ela é também um fator extremamente impor- 
tante do sentimento de continuidade e de coerência de uma pessoa ou de um grupo em sua reconstrução de si (POLLAK, 1992, p. 204).

Do ponto de vista do antropólogo, para Joel Candau a questão da ligação entre memória e identidade não difere muito das considerações feitas por Pollak. Candau (2016) apresenta a relação dialética entre memória e identidade, uma vez que " a memória é uma instância que molda o ser humano, é também pelo ser humano moldada conforme o lugar onde este se encontre" (CANDAU, 2016, p. 16). O autor também apresenta à dificuldade de se trabalhar a memória coletiva e a memória individual questionando quais seriam os elementos constituintes da memória individual e coletiva, e a relação entre memória individual, coletiva na construção da identidade. Como a memória individual passa a fazer parte, interagir, coabitar na memória do grupo? Falar de uma memória coletiva e acreditar que ela exista de fato, para Candau (2016), é possível apenas no campo teórico, discursivo; no campo material, concreto, essa categoria não se aplica, visto que uma memória coletiva é construída a partir de memórias majoritárias sobrepostas e que, com o tempo e a tradição, se constituem hegemônicas na configuração do grupo com o objetivo de manter a unidade, criar sentimento de pertencimento. Candau, nesse ponto, constrói um debate estruturalista.

Qual viria a ser a contribuição dos estudos analisados e suas potencialidades para a Geografia, especialmente a Geografia Agrária? Refere-se aqui à possibilidade de se analisar a memória e/ou identidade como conceitos da pesquisa geográfica, visto que diversos trabalhos da Geografia Cultural e da Geografia Crítica exploram esses aspectos quando analisam o espaço, o território, o lugar e demais conceitos chave para a ciência geográfica. Nesse sentido é essencial que entenda-se como se formam, se constroem e se reconstroem as identidades no espaço a partir da memória. Candau afirma que

... a presença do passado no presente é bem mais complexa, bem menos explícita, mas talvez bem mais forte que a existência de narrativas explícitas nos poderia fazer crer. O que não é expresso nas lembranças manifestadas [...] tem significação social pois se trata de um ativo colocado em reserva para futuras representações sociais (CANDAU, 2016, p. 33-34).

Exemplo disto é o movimento Sertanejo do Contestado, que marcou profundamente a sociedade do interior de Santa Catarina e do Paraná. Passados mais de cem anos do final da Guerra do Contestado (1912-1916) tal memória camponesa ainda é recordada na contemporaneidade e é também criadora de identidades. Esta memória, passada por gerações, não faz parte da memória oficial - organizada, gestionada e construída pelo Estado - visto que até a década de 1950 as pesquisas sobre o movimento eram exclusivamente de domínio do Exército Brasileiro. Essa memória institucionalizada teve influência do silêncio dos caboclos, descendentes dos guerreiros do Contestado, na medida em que produzia um discurso atribuindo suas atitudes a um fanatismo religioso, a ignorância e a barbárie (MACHADO, 2012). 


\section{IDENTIDADE NA CONSTRUÇÃO DO CAMPESINATO ENQUANTO CLASSE}

Entender o campesinato em sua realidade é algo complexo, mas como cita Hobsbawm (1973, p. 03), definindo campesinato: "Pode ser um assunto muito complexo para um zoologista definir um cavalo, mas isso normalmente não significa que existe alguma dificuldade real em reconhecer $\mathrm{um}^{\prime \prime}$. As diversas faces campesinas se traduzem em sujeitos sociais peculiares no modo de produção capitalista. Portanto, como traz Bartra (2011, p. 14) “o campesinato só pode ser pensado através da diversidade. Existem desde camponeses clássicos até os neorrurais e os povos originários". O campesinato vai ser trabalhado aqui em sua polifonia.

Os camponeses estão em questionamento há muito tempo, seja na academia, nos movimentos sociais ou em seu cotidiano. Desde o século XIX, diversos intelectuais buscaram compreender seu papel na sociedade sob o modo de produção capitalista, passando por Karl Marx, Georgi Plekhanov, Vladimir Lenin, Karl Kautsky, dentro do Marxismo; Nikolai Chernyshevsky e Nikolai Mikhaylovsky no Populismo (Narodismo) russo; Mikhail Bakunin e Piotr Kropotkin no Anarquismo. Os debates, de cunho crítico, se davam em torno da importância e vigência do campesinato sob o modo de produção capitalista. Este trabalho concorda com Shanin (1983), encarando o campesinato como classe social sui generis do capitalismo e como modo de vida. Contudo, o questionamento que aqui buscamos é estabelecer a importância da identidade para a classe camponesa. Assim sendo, cabe afinal definir o que se compreende como campesinato. Para Bartra (2011, p. 67-69) o camponês "é um pouco fazendeiro, um pouco burguês e um pouco operário". Ainda segundo Bartra (2011, p, 72), os camponeses compreendem "o trabalhador rural autônomo com algum acesso a terra".

Trabalhar o camponês somente do ponto de vista do indivíduo é inviável para uma análise coesa. Novamente Bartra nos auxilia ao citar que o campesinato é um emaranhado de relações sociais, cujos nós são a comunidade, a vila rural, o povoado, a família, etc.

No caso do Brasil, o campesinato foi formado as margens da sociedade escravista (MARTINS, 2015). Como nos mostram Marques (2008), Almeida (2006) e Paulino (2012), o campesinato brasileiro apresenta como diferencial do campesinato europeu, por exemplo, a mobilidade espacial, uma vez que na Europa tal classe estava muito bem enraizada na terra. Almeida (2006, p. 288) cita como motivo para tal mobilidade o bloqueio histórico de acesso a terra, além de um desejo permanente de parte deste campesinato de enraizamento. Logo, para Wanderley (1999) o modo de vida camponês é anterior e muito mais forte que a própria construção classista destes sujeitos. Esse modo de vida é mutável e variável. É um contínuo de mudanças e construções que se dá na diversidade de espaços e territórios que são conquistados por esse campesinato, a duras penas e muitas vezes ao custo de sangue. Conforme Paulino (2012, p. 46):

Ao situar a origem do campesinato brasileiro na Idade Moderna, momento em que a lógica capitalista já está incrustada em todas as relações, admite-se que tal lógica

1 No original: "It may well be a very complex matter for a zoologist to define a horse, but this does not normally mean that there is any real difficulty about recognizing one." 
impulsiona a territorialização dos europeus, processo eufemisticamente denominado civilizador, mas que implicou em violenta desterritorialização dos povos nativos, pari passu ao contato. [...] A busca de terra livre tem sido resposta ao histórico processo de expulsão e migração imposto pelo próprio avanço do capital.

Almeida (2006) apresenta como uma das especificidades campesinas a repetição de experiências concretas que permitem a reprodução das relações sociais e criação de novas relações. Ou seja, mesmo estando na luta constante por obtenção ou manutenção de sua terra, o campesinato tem em si a construção de seu território de vida, baseado na terra, um horizonte futuro e ao mesmo tempo uma realização pretérita. Sobre isso, apresenta a autora:

[...] quando admitimos a territorialização como distinção, não descartamos o entendimento do campesinato como horizonte no qual é possível compreender a luta política e o sentido de classe desses agentes. A classe camponesa que se reproduz no capitalismo é diametralmente oposta ao camponês servo. Sua (re)criação se faz contraditoriamente como relação não-capitalista, na medida que o capital convive com sua expansão. Todavia, esse mesmo capital cobra seu tributo subordinando a renda da terra e recebendo do campesinato a resposta por meio da luta de resistência. (ALMEIDA, 2006, p. 210).

A luta pela terra é, portanto, o conflito central do campesinato. É "o conflito entre a propriedade privada camponesa e a propriedade privada capitalista" (ALMEIDA, p. 252) - a luta entre a classe camponesa e a classe dos proprietários de terra. Tal luta não se limita ao Brasil e perpassa a América Latina como um todo. Citando Bartra (2011), entende-se aqui que, apesar de ter um início diferenciado do europeu, o campesinato latino de modo geral a mesma centralidade. Bogo (2013) discorre que a construção da classe camponesa, no âmbito latino, vai sendo feita através de suas lutas por terra e território, e tem na figura da Via Campesina (VC) o movimento articulador de identidades e memórias. Mesmo que a VC tenha sido criada somente em 1993, é ela que congrega as memórias e experiências de diversos grupos camponeses ao largo do globo, servindo não só de movimento político e social, mas também de guardiã das memórias camponesas. Tal movimento permite a troca de experiências, memórias, ferramenta de modificação de identidades.

Pontua-se que o campesinato é uma classe social além de um modo de vida. Chayanov (1985) destaca que a manutenção da autonomia, do bem estar familiar e o entendimento da terra como local de trabalho e (re) produção da vida são características ímpares na construção desses sujeitos. Shanin (1983) elenca novamente que o campesinato não pode ser entendido como uma generalização, não pode ser homogeneizado. Ainda para Shanin, o campesinato se entende como classe em momentos de crise, quando sua diferenciação interna é posta de lado, onde a coesão da classe se torna clara e evidente. Logo, o campesinato só se constrói enquanto classe, com características que lhes são caras e particulares, através da luta de classes. Por classe entendemos um processo pelo qual "alguns homens, como resultado de experiências comuns (herdadas ou compartilhadas), sentem e articulam a identidade de seus interesses entre eles e contra outros" (THOMPSON, 1979, p. 10). 
Posto isso, Thompson ressalta o entendimento central da importância da memória e da identidade para o campesinato, seja em suas lutas, na sua construção enquanto classe ou enquanto sujeitos sociais marcantes e indispensáveis ao modo de produção capitalista. O fato novo que Thompson (1979) insere é a quebra da lógica ortodoxa de construção da classe somente pelo viés da luta entre os donos do meio de produção e os trabalhadores: o autor acrescenta a experiência adquirida, a memória como elementos importantes e presentes na elaboração das lutas.

As lutas camponesas, ainda que isoladas ou não unificadas, acabam por serem importantes para a construção da classe camponesa. Exemplo vivo são os camponeses do Contestado, cuja memória da Guerra e do massacre sofrido por seus ancestrais é o elemento central da construção de sua identidade enquanto 'caboclos do Contestado'. Os sujeitos de hoje usam do 'ontem' para construir sua luta por terra, território e autonomia. A identidade cunhada com o sangue de seus ancestrais através da memória é o motor da luta de classes, a qual unifica tais sujeitos enquanto camponeses massacrados pelo Capital, pelos proprietários de terra e pela burguesia, tanto no ontem como no hoje. Isso corrobora Bartra (2011, p. 320):

Com a classe não se nasce, a classe se faz. Ela se constrói na luta, quando o passado comum e a experiência compartilhada ganham sentido identitário. Se para os operários é árduo tornar-se classe, muito mais será para os camponeses, já que são constituídos por uma variada multidão de trabalhadores rurais sujeita às mais diversas relações econômicas, que vão desde a produção independente até o trabalho assalariado, além de uma heterogênea experiência social que os leva de uma comunidade tradicional às metrópoles do Primeiro Mundo.

A própria luta de classes é forjada, também, pela memória e pela identidade. No caso do campesinato, os usos e os costumes são recursos essenciais na defesa e preservação de suas identidades e memórias, organizadas a partir do conflito, da distancia e da resistência (BARTRA, 2011). A identidade camponesa em si mesma já é conflituosa com o Capital. A manutenção de seus territórios de vida, seu entendimento da terra não como local de extração de renda, mas sim como territórios de trabalho e de vida, fazem com que as ações desses sujeitos sejam em si mesmas um ato de resistência.

Para Bogo (2013) a classe camponesa no Brasil segue em construção, pois as lutas camponesas ainda são parte do cotidiano nacional e as identidades vão se modificando com este movimento. Cita o ainda Bogo (2013, p. 117): “A identidade, seja ela individual ou coletiva, é parte constitutiva do movimento dialético já feito, antecipando a expectativa do movimento que ainda fará a nova identidade".

Isto é visível no desenrolar dos conflitos agrários no Brasil, como o caso do movimento social dos povos faxinalenses, ainda restrito ao Estado do Paraná, a Articulação Puxirão dos Povos Faxinalenses (APF). Este movimento forja a identidade de faxinalenses através de sua luta contra o agronegócio, a luta pela manutenção de sua autonomia e seu território, além da constante demanda por políticas públicas voltadas para sua produção agrícola. Podemos citar a Rede Puxirão dos Povos e Comunidades Tradicionais, movimento social 
que articula distintos grupos sociais, camponeses, étnicos ou religiosos, todos marginalizados pelo Estado Brasileiro, onde se encontram os xetás, guaranis, kaingangs, faxinalenses, quilombolas, benzedeiras e benzedores, pescadores artesanais, cipozeias, caiçaras, religiosos de matriz africana e ilhéus. Abarcando diferentes identidades e grupos sociais, tal movimento social busca articular tais grupos nos Estados do Paraná e Santa Catarina, e acaba por auxiliar na construção de novas identidades, através da luta e troca de memórias.

Os conflitos da luta de classes redefinem e reconstroem identidades campesinas que estavam, até certo ponto, isoladas. É o movimento da 'classe em si' para a construção da 'classe para si', tão caro a Marx. Consequentemente:

Podemos, portanto, dizer que a classe camponesa, embora exista como dado objetivo (classe no papel), sua consciência de classe é uma potencialidade não como derivação da consciência operária moldada no confronto Capital - Trabalho, mas na contradição camponesa que, no limite, pode fazer de sua resistência contra a expropriação uma luta anticapitalista (ALMEIDA, 2006, p. 253).

Reforçamos que a identidade e a memória do campesinato são essenciais para sua construção enquanto classe. Ferramentas presentes na própria luta de classes, expressas nos conflitos territoriais que o campesinato trava contra seus antagonistas, sejam eles o Estado, o agronegócio ou os capitalistas. A centralidade da manutenção do autossustento familiar, da autonomia relativa e de multifacetados modos de vida camponeses passa, indiscutivelmente, pela manutenção, ampliação e fortalecimentos dessas memórias e identidades, sujas de sangue, sofridas e tão marginalizadas no espaço agrário brasileiro e latino americano.

\section{O TERRITÓRIO CAMPONÊS: RESISTÊNCIAS, MEMÓRIAS E IDENTIDADES}

Como Oliveira (2002) apresenta, existe uma centralidade no território como tema de pesquisa na corrente crítica da Geografia Agrária. Por conseguinte analisamos o desenrolar e a importância da memória e da identidade com o campesinato trabalhando com a expressão territorial de tal fato. Compreendemos a construção do território como:

[...] simultaneamente, construção/destruição/manutenção/transformação. É, em síntese, a unidade dialética, portanto, contraditória, da espacialidade que a sociedade tem e desenvolve. Logo, a construção do território é, contraditoriamente, o desenvolvimento desigual, simultâneo e combinado, o que quer dizer: valorização, produção e reprodução. (OLIVEIRA, 2002, p. 40).

Concebe-se que a construção dos territórios camponeses pelo Brasil e América Latina são expressões dessas contradições do próprio modo de produção capitalista. Cada território camponês tem em seu âmago diversas características particulares. Como apresenta Saquet (2007), o território em si é pluridimensional, abarcando elementos políticos, culturais, sociais, econômicos e ambientais. Acrescenta-se que a construção territorial possui o elemento da identidade como indispensável. Apesar de todos estes territórios estarem 
inseridos dentro de um território ainda maior, o do modo de produção capitalista, cada um deles possui características que lhes são particulares e estas passam pela identidade da comunidade.

O território é também entendido como a expressão dos atores sociais, ou seja, um produto social construído histórica, econômica, política e socialmente (RAFFESTIN, 1993). O território é então a expressão da sociedade no espaço, delimitado pelas relações de poder, entendidas a partir da luta de classes em suas várias escalas, desde a luta em si, passando pelas disputas políticas, conflitos de interesse e de racionalidade.

Cada território, portanto, têm conectado a si uma identidade própria. Os territórios camponeses podem ter marcas identitárias que lhes são indissociáveis. É notável tal presença nos territórios caboclos do Contestado, onde marcos tanto materiais quanto imateriais, transmitidos pela memória, são parte importante na construção territorial de tais sujeitos. Outro exemplo é observado nos territórios de comunidades camponesas que tem no uso comum da terra sua ferramenta de produção. Tal ferramenta, porém, não se limita ao marco produtivo somente, ela perpassa a construção identitária e é também elemento essencial da própria reprodução da vida desses sujeitos.

É caro à Geografia Agrária considerar que "as múltiplas identidades camponesas estão, através da resistência e da luta por seus territórios de vida, (re)articulando e fortalecendo as diferenças existentes entre si mesmos, utilizando isto como instrumento de fortalecimento da identidade da classe como um todo" (BARTRA, 2011, p. 141). Outro ponto de destaque é que tanto o modo de produção capitalista quanto o campesinato carecem de uniformidade (AMIN, 1977), não sendo possível pensar em uma homogeneidade de classe, mas sim na formação da classe para si através das lutas e que as diferenças de identidades sejam um elemento de fortalecimento desses sujeitos.

O campesinato é uma classe com potencial contestador e de resistência às mazelas do Capital, tendo no Estado, como agente do Capital, um adversário constante, uma vez que suas identidades diferem. Sendo assim:

A utopia camponesa é a aldeia livre, livre de coletores de impostos, livre de recrutadores de força de trabalho, de grandes proprietários e funcionários. Governados, sem jamais governar, falta-lhes a familiaridade com a complexa maquina de operações estatais, que apenas percebem como "um monstro frio". [...] Para o camponês, portanto, o Estado é uma quantidade negativa, um mal a ser substituído a toque de caixa, por sua própria ordem social "feita em casa". Acreditam que essa ordem pode funcionar sem o Estado, pois os camponeses rebeldes são anarquistas inatos. (WOLF, 1984, p. 352-353).

Entende-se que o campesinato em si, com suas identidades diversas e polifônicas, com sua compreensão diferenciada de mundo, com sua construção territorial particular, com seu desdém ao lucro e seu apreço à comunidade e à família já lhes consagra o papel de rebeldes natos. Como Scott (1990) a resistência e a rebeldia camponesa se dá no próprio cotidiano destes sujeitos. O simples fato de tal classe (re)existir é um ato de rebeldia 
e confronto com o modo de produção capitalista. A identidade e a memória da classe são ferramentas de resistência.

\section{CONSIDERAÇÕES FINAIS}

A tratativa deste artigo era apresentar e discutir a importância da identidade e da memória para a classe camponesa e os desdobramentos disto na realidade. A compreensão do campesinato enquanto classe que constrói seus territórios de vida em constante conflito e resistência perante o capital são mostras de como os elementos do ontem são fundamentais para a construção do hoje camponês.

Ao ser construída dialeticamente, as identidades se modificam, se (re)constroem cotidianamente. A luta de classes é a maneira na qual a classe camponesa para a se perceber para si. As memórias são intercambiadas entre a variedade de camponeses e camponesas. A identidade é atualizada constantemente: o que ontem era impensável hoje é discutido nas comunidades, como a questão de gênero, a agroecologia, a própria identidade particular de cada grupo, a questão racial. Isso demonstra como a identidade não é estanque, mas sim em constante movimento, rebelde e contestatório.

A expressão destes grupos no espaço através de seus territórios de vida é marco cravado na terra, entendida como território pluridimensional para tal classe, a qual com muito sangue, suor, luta e resistência permanece como componente chave do campesinato. Ao entender a terra como território, terra como local de vida, trabalho e sociabilidade, não como mero local de extração de renda, define-se tal classe como única.

Em vista disto, destaca-se novamente que não existe conflito em considerar as mais variadas identidades e memórias na construção do campesinato enquanto classe. Formar a unidade de classe não é sinônimo de homogeneizar a riqueza que a diferença interna nos apresenta. O ontem e o hoje conversam dialeticamente, buscando a construção de um amanhã mais justo e igualitário na diferença.

\section{REFERÊNCIAS}

ALMEIDA, Rosemeire Aparecida. (Re)criação do campesinato, identidade e distinção: a luta pela terra e o habitus de classe. São Paulo: Ed. UNESP, 2006.

AMIN, Samir. O Capitalismo e a renda fundiária (A dominação do capitalismo sobre a agricultura). IN: AMIN, Samir; VERGOPOULOS, Kostas. A questão agrária e o capitalismo. 2 ed. Rio de Janeiro: Paz e Terra, 1977.

BARTRA, Armando Vergés. Os novos camponeses. Leituras a partir do México Profundo. São Paulo: Cultura Academica/ Cátedra UNESCO de Educação do Campo e Desenvolvimento Sustentável, 2011.

BOGO, Ademar. Identidade e luta de classes. 2.ed. São Paulo: Expressão Popular, 2013. (Debates \& Perspectivas).

CANDAU, Joel. Memória e identidade. 3. Reimpr. São Paulo: Contexto, 2016.

CHAYANOV, Alexander. La organización de la unidad econômica campesina. Buenos Aires: Nueva Visión, 1985. 
HALL, Stuart. Introduccion: quién necessita 'identidad'? In: ; GAY, Paul Du. (Orgs.) Cuestiones de identidad cultural. Buenos Aires: Amorrortu editores, 2003 [1996]. p. 13-39.

MACHADO, Paulo Pinheiro. O Contestado e o mundo caboclo: história, memória e historiografia. In: VALENTINI, Delmir José; ESPIG, Márcia; Nem fanáticos, nem jagunços: reflexões sobre o Contestado (1912-2012). Pelotas: UFPEL, 2012. p. 15-27.

MARQUES, Maria Inês Medeiros. A atualidade do uso do conceito de camponês. Revista NERA, Presidente Prudente, v. 11, n. 12, p. 57-67, jan.-jun. 2008.

MARTINS, José de Souza. O cativeiro da Terra. 9.ed., 2. reimp. São Paulo: Contexto, 2015.

OLIVEIRA, Ariovaldo Umbelino. O século XXI e os conflitos no campo: modernidade e barbárie. Goiânia: Edições Loyola, 2002. (Conflitos no Campo Brasil 2001, p. 26-29). Disponível em: https:/ / www.agb.org.br/ publicacoes/index.php/terralivre/article/download/531/497. Acessado em: 10 maio 2018.

PAULINO, Eliane Tomiasi. Por uma Geografia dos camponeses. 2.ed. Presidente Prudente: Ed. UNESP, 2012.

POLLAK, Michael. Memória, Esquecimento, Silêncio. Estudos Históricos, Rio de Janeiro, v. 2, n. 3, p. 3-15, 1989.

. Memória e Identidade Social. Estudos Históricos, Rio de Janeiro, v. 5, n. 10, p. 200-212, 1992.

RAFFESTIN, Claude. Por uma Geografia do Poder. São Paulo: Ática, 1993.

SAQUET, Marcos Aurélio. Abordagens e concepções de território. São Paulo: Expressão Popular, 2007.

SCOTT, James. Weapons of the Weak: everyday forms of peasant resistence. New Haven/ London: Yale University Press, 1990.

SHANIN, Teodor. La clase incómoda. Madrid: Alianza Editorial, 1983.

SILVA, Kalina Vanderlei; SILVA, Maciel Henrique. Dicionário de conceitos históricos. 2. Ed.. São Paulo: Contexto, 2009.

THOMPSON, Edward Palmer. Tradición, Revulta y Consciência de Clase. Barcelona: Crítica, 1979.

WANDERLEY, Maria Nazareth Baudel. Raízes Históricas do Campesinato Brasileiro. In: TEDESCO, João Carlos (Org.). Agricultura familiar: realidade e perspectivas. Passo Fundo: Universidade de Passo Fundo, 1999.

WOLF, Eric. Guerras Camponesas do século XX. São Paulo: Global, 1984.

Data de submissão: 18/nov./2017

Data de aceite: $11 /$ maio/2018 